\title{
Originals
}

\section{Prevalence and development of retinopathy in children and adolescents with Type 1 (insulin-dependent) diabetes mellitus. A longitudinal study}

\author{
W. Burger ${ }^{1}$, G. Hövener ${ }^{2}$, R. Düsterhus ${ }^{1}$, R. Hartmann ${ }^{1}$ and B. Weber ${ }^{1}$ \\ ${ }^{1}$ Free University Children's Hospital, Klinikum Charlottenburg and \\ ${ }^{2}$ Free University Eye Clinic, Klinikum Steglitz, West Berlin
}

\begin{abstract}
Summary. In 231 subjects with Type 1 diabetes mellitus aged $17.6 \pm 4.0$ years, with a diabetes duration of $8.5 \pm 4.9$ years at the end of the study, the prevalence and the development of retinopathy during a period of 5 years were studied. All patients were examined between one and six times both by ophthalmoscopy and fluorescein angiography. A total of 626 fluorescein angiographies were evaluated. By the end of the study, 109 out of 231 patients $(47 \%)$ had developed retinal changes, half of which were classified as minimal $(<$ 5 microaneurysms). Thirty-eight patients ( $35 \%$ of those affected) had background $(n=28)$ or proliferative $(n=10)$ retinopathy. In subjects less than 15 years of age and diabetic for less than 5 years, retinal lesions were rare. With increasing age and duration of diabetes, both the prevalence and severity of retinal changes increased markedly. Life-table analysis was used
\end{abstract}

to calculate the median individual risk for the development of early retinal changes, which was 9.1 years of diabetes duration. This risk differed in sub-groups with different ages at onset of diabetes, i.e. $12.1,8.9$ and 6.6 years $(p<0.0001)$, with diabetes starting below 4 , between 5 and 9 , and after 10 years of age respectively. After 18 years of diabetes, every patient demonstrated at least incipient structural changes. Fluorescein angiography allowed the detection of retinopathy, on average, four years earlier than with ophthalmoscopy. The median interval between the 'onset' of retinopathy, as indicated by a few microaneurysms, and background retinopathy was 5 years.

Key words: Retinopathy, fluorescein angiography, insulin-dependent diabetes, children and adolescents.
The rate of progression of microangiopathy is of major prognostic importance to every Type 1 (insulin-dependent) diabetic patient [1-3]. Therefore, information about the early development of retinal changes occurring in the first few years after diagnosis of diabetes are important. It is also likely that retinopathy may represent concomitant microvascular changes in other organs which are more difficult to assess.

The present mixed cross-sectional and longitudinal study attempted to detect early retinal changes in a representative sample of Type 1 diabetic children and adolescents, and to determine the prevalence of retinopathy in this age group, the dynamics of its development, and some of the factors influencing its course.

\section{Subjects and methods}

In 231 Type 1 diabetic patients (119 males, 112 females), the retinal status was longitudinally documented (once every 12 to 14 months) by both ophthalmoscopy and fluorescein angiography from 1977 to 1982. Their mean age $\pm S D$ was $17.6 \pm 4.0$ (range 8.6 to 32.5 years), and their diabetes duration was $8.5 \pm 4.9$ (range 0.5 to 23 years) at the end of 1982 (Fig.1). All patients attended the outpatient clinic of the Free University Children's Hospital in West Berlin an average of every 4 to 8 weeks, and were all treated similarly during the study period. Their treatment aim was physical and psychological health and well-being, normal activity, absence of severe hypoglycaemia, and glycaemic control as close to the normal range as achievable by conventional therapy. Insulin (intermediate-acting or mixtures of intermediate- and short-acting, highly purified preparations) was administered twice daily, with a mean \pm SD dose of $0.8 \pm 0.3 \mathrm{IU} / \mathrm{kg}$ body weight/day. Food intake was calculated individually. Extra food was prescribed for unusual physical activity. The (carbohydrate-fixed) diet, adapted to the patient's individual and culturally-determined eating habits, generally consisted of $45-50 \%$ carbohydrates, $30-35 \%$ ( $40 \%$ with high energy requirements) fat $(\mathrm{P} / \mathrm{S}$ ratio about 1$)$, and $15 \%$ protein ( $20 \%$ in younger children).

At the outpatient visits we recorded the results of the physical examination, blood pressure, fundoscopy without pupillary dilatation, 1- to 2-h post-prandial (afternoon) blood glucose, and 24-h glycosuria of the preceding day. The results of home-monitoring (usually of glycosuria and less frequently of blood glucose) were recorded and evaluated between the doctors and the patients and/or their parents. Glycosylated haemoglobin (microcolumn method, Isolab Fast Haemoglobin Test System, Kleinwallstadt, FRG) and urinary protein excretion were measured every 3 months; fasting serum cholesterol and triglycerides, serum transaminases and creatinine clearance were measured annually.

Between 1977 and 1981, all cooperating children and adolescents (older than 7 years of age) were examined by both ophthalmoscopy and fluorescein angiography, in general once every year, by one of the authors (G.H.). Informed consent was given by the patients and/or their parents. Following a preliminary evaluation of the results of the first fluorescein angiography examinations in the sample, which demonstrated only a few incipient abnormalities in children younger than 15 years and diabetic for less than 5 years, these subjects were excluded from further examinations until either age or diabetes duration had exceeded these limits. After inspection of the fundus with dilated pupils, angiography was performed with an injection of $10 \%$ sodiumfluorescein solution $(1 \mathrm{ml} / 10 \mathrm{~kg}$ body weight) over 2 to $3 \mathrm{~s}$, followed $6 \mathrm{~s}$ later by a series of photographs of the right ocular pole at intervals of $1.5 \mathrm{~s}$. Following another injection of $1 \mathrm{ml}$ of the contrast medium, stereophotographs of both ocular poles were performed. The examination was terminated by photographs after $5 \mathrm{~min}$ [4]. No major complications were registered. Ten percent of the subjects had slight nausea, and only one patient developed urticaria. This last patient was excluded from further fluorescein studies. Photographs were taken with a Zeiss-Fundus-Kamera with Kodak-Plus x-Pan or Ilford FP4 film. 

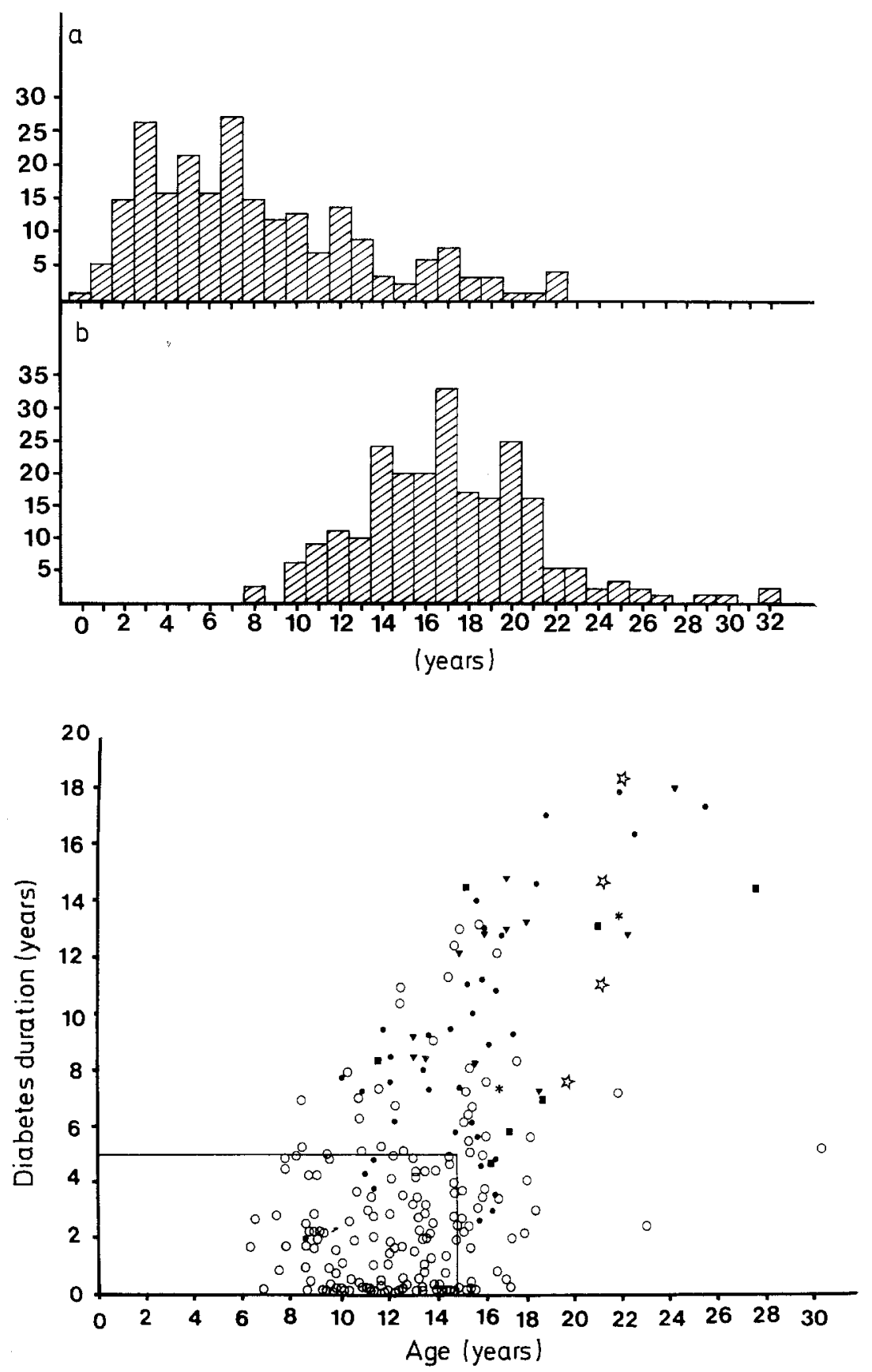

Fig. $1 \mathrm{a}$ and $\mathbf{b}$ Distribution by age (b) and diabetes duration a of 231 Type 1 (insulin-dependent) patients who were longitudinally studied by fluorescein angiography as of 31 December 1982
Fig. 2. Stage of retinopathy, age and duration of diabetes at first fluorescein angiography in 231 patients. Among 117 patients less than 15 years of age and with diabetes for less than five years, only four subjects ( $3 \%$ ) exhibited minimal (stage 1) lesions (see insert). $\mathrm{O}=$ stage $0, \boldsymbol{O}=$ stage $1, \mathbf{\square}=$ stage $2, \boldsymbol{\nabla}=$ stage $3 \mathrm{a}$, $*=$ stage $4 \mathrm{a}$, stage $4 \mathrm{~b}$
Table 1. Distribution of the different stages of retinopathy as found by fluorescein angiography at the end of the study

\begin{tabular}{|c|c|c|c|c|c|}
\hline \multicolumn{2}{|l|}{ Stage } & \multirow{2}{*}{$\begin{array}{l}\begin{array}{l}\text { No. of } \\
\text { patients }\end{array} \\
122\end{array}$} & \multirow{2}{*}{$\begin{array}{l}\% \\
\\
52.8\end{array}$} & \multirow{2}{*}{$\begin{array}{l}\begin{array}{l}\text { Duration } \\
\text { (years) } \\
\text { Mean } \pm \\
\text { SD }\end{array} \\
5.4 \pm 2.6\end{array}$} & \multirow{2}{*}{$\begin{array}{l}\text { Age (years) } \\
\text { Mean } \pm S D \\
16.1 \pm 3.6\end{array}$} \\
\hline 0 & \multirow{3}{*}{ Minimal } & & & & \\
\hline 1 & & 54 & 23.4 & $10.7 \pm 4.8$ & $18.3 \pm 3.7$ \\
\hline 2 & & 17 & 7.4 & $13.1 \pm 4.9$ & $20.3 \pm 4.0$ \\
\hline $3 \mathrm{a}$ & \multirow{3}{*}{ Background } & 22 & 9.5 & $13.0 \pm 3.9$ & $19.0 \pm 3.8$ \\
\hline $3 b$ & & 6 & 2.6 & $12.6 \pm 4.7$ & $21.0 \pm 2.7$ \\
\hline $4 a$ & & 6 & 2.6 & $13.0 \pm 2.1$ & $20.6 \pm 2.5$ \\
\hline $4 b\}$ & \multirow[t]{2}{*}{ Proliferative } & 4 & 1.7 & $16.2 \pm 4.2$ & $24.4 \pm 1.0$ \\
\hline \multirow[t]{2}{*}{$4 c)$} & & 0 & 0 & $-\quad-$ & $-\quad-$ \\
\hline & & 231 & 100.0 & $8.5 \pm 4.9$ & $17.6 \pm 4.0$ \\
\hline
\end{tabular}

Two hundred and thirty-one patients received at least one, 172 at least two, 116 at least three, 75 at least four, 29 at least five, and 3 patients six angiographies, for a total of 626 examinations. Glossy prints $(13 \times 18 \mathrm{~cm})$ were evaluated by three of the authors $(G . H$., W. B. and B.W.) independently. Discrepancies of interpretation were discussed, respective abnormalities were sought in the negatives, and these $a b$. normalities were compared with findings in previous photographs of the same eye. Doubtful findings were excluded from the analysis.

We modified Malone's classification of fluorescein angiographic findings [5] to yield 8 (instead 5) stages: (0) no changes; (1) 1-5 microaneurysms in one eye; (2) 6-10 microaneurysms; (3a) 11-50 microaneurysms $+<25$ leakages; $(3 \mathrm{~b})>50$ microaneurysms $+>25$ leakages; (4a) intraretinal, (4b) preretinal, and (4c) epiretinal neovascularisations. This modification was better at discriminating between incipient, background, and proliferative retinopathy, and was used for both ophthalmoscopic and angiographic findings. 


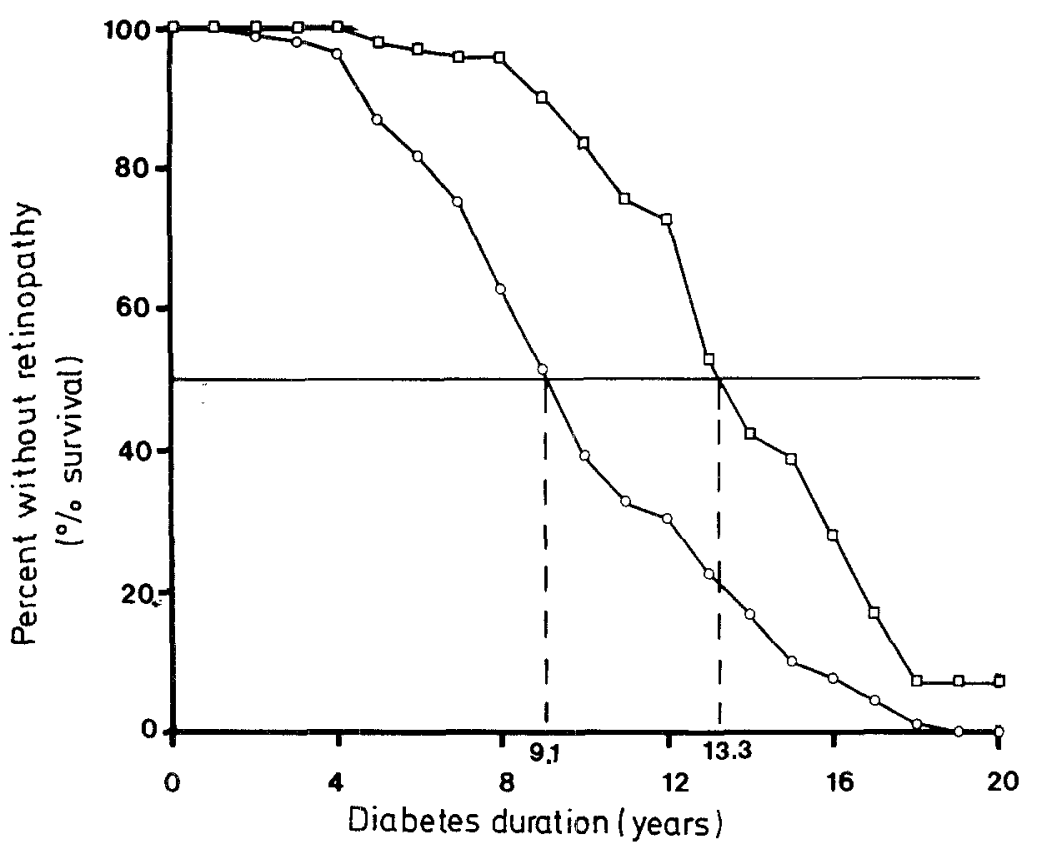

Fig.3. Life-table analysis of fluorescein angiographic and ophthalmoscopic retinal findings in 231 patients. The 'survival' function in this study indicates the duration of diabetes before the development of retinal lesions. The median risk (or latency period between the onset of diabetes and the detection of retinopathy) depicted by the horizontal line at $50 \%$ survival for any subject in this sample was calculated as 9.1 years until detection by fluorescein angiography and 13.3 years until detection by ophthalmoscopy. $O=$ fluorescein angiography, $\square=$ ophthalmoscopy

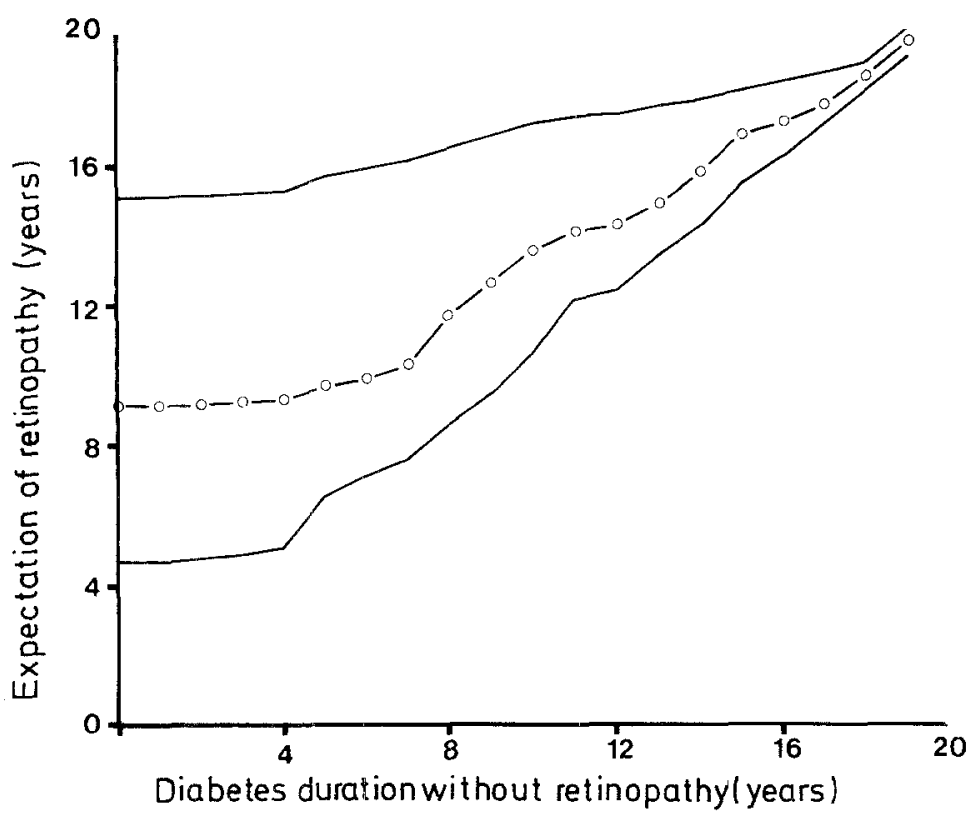

Fig.4. Expectation of fluorescein angiographic positive retinal lesions with time (years) depending upon previous duration of diabetes without retinopathy as calculated by lifetable analysis. The convergence of the percentile curves with longer duration of diabetes indicates that duration, with time, becomes the most important, if not the only, determinant of the development of retinopathy. $\stackrel{-}{-}=10^{\mathrm{th}}$ and $90^{\mathrm{th}}$ centile lines and $\mathrm{O}-\mathrm{O}=50^{\mathrm{th}}$ centile line

\section{Statistical methods}

The dynamics of the development of retinopathy and its association with different variables were evaluated by means of life-table analysis using LEE DESU statistics [6]. This analysis is event-oriented and uses all available data to determine when this event occurs. In this study, it permitted the calculation of the individual patient's risk of developing various stages of retinopathy, expressed in years from the onset of diabetes, i.e. the latency period between presentation with diabetes and the appearance of retinal lesions. Since 62 out of 231 patients $(27 \%)$ had changes at their first fluorescein angiography examination, their transition from negative to positive findings, or from one stage to another, was missed. Therefore, the true mean latency period for the development of retinopathy is shorter than that calculated from this data.

The influence of various factors on the prevalence of retinopathy was calculated by means of cross-sectional analyses using the Chisquare test, Student's t-test, and regression analysis.

\section{Results}

The results of all the first fluorescein angiography examinations and their relationship with age and diabetes duration are shown in Figure 2. As expected, both prevalence and severity of retinal changes increased with age and diabetes duration. In children less than 15 years of age and diabetic for less than 5 years, only 4 subjects (out of $117=3 \%$ ) had stage 1 (minimal or incipient) changes. Following these preliminary results, annual fluorescein angiographies were no longer felt to be justified in subjects with these characteristics.

During the 5-year course of this study, 109 out of 231 patients $(47 \%)$ were found to exhibit fluorescein angiographically with positive retinal changes. Their frequency was estimated to be $14 \%$ after 5 years, $67 \%$ after 


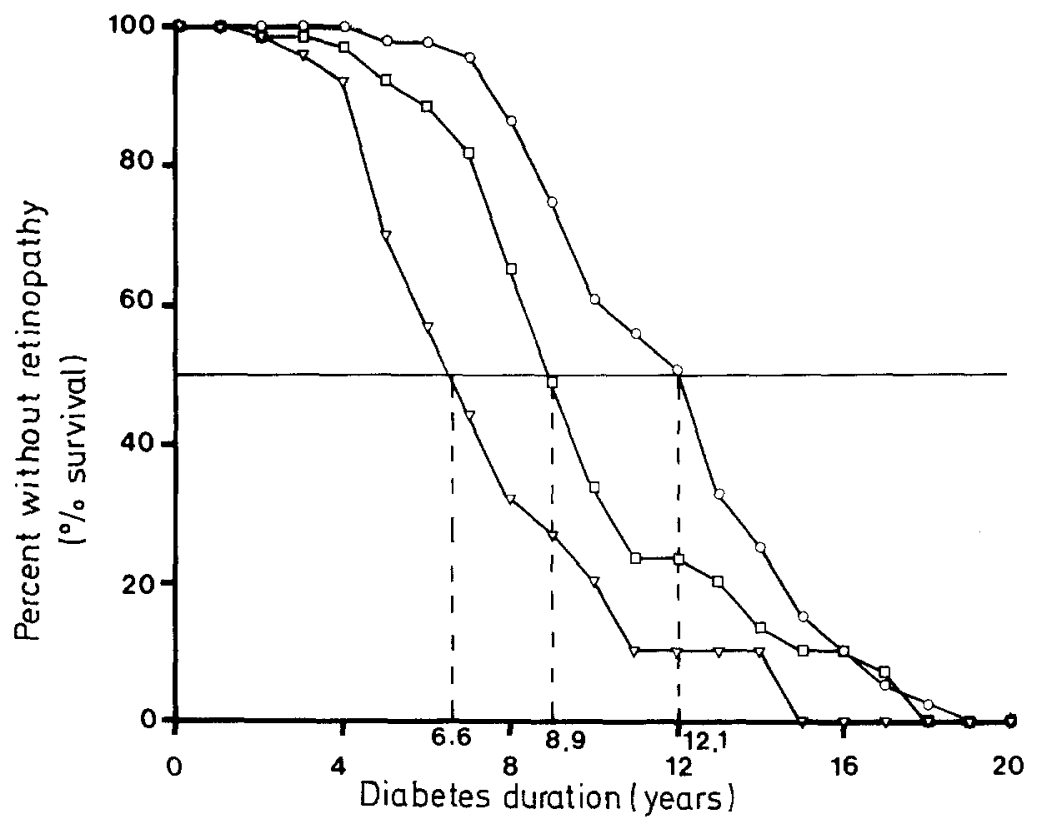

Fig. 5. Life-table analysis of fluorescein angiographic findings in 231 patients divided into 3 sub-groups with different age at onset of diabetes. The median latency (horizontal line) for the development of fluorescein angiographic positive lesions decreased from 12.1 to 6.6 years with increasing age at onset of diabetes $(p<$ 0.0001 ).

$O=0-4$ years, $\square=5-9$ years, $\nabla=\geqslant 10$ years
Table 2. Median expectation of early retinopathy (life-table analysis)

\begin{tabular}{lrlll}
\hline \begin{tabular}{l} 
Age at onset $\begin{array}{l}\text { of diabetes } \\
\text { (years) }\end{array}$ \\
\cline { 3 - 5 }
\end{tabular} & $\begin{array}{l}\text { Stage 1 } \\
(\text { minimal) } \\
(p<0.0001)\end{array}$ & $\begin{array}{l}\text { Stage 3 } \\
\text { (background) } \\
(p<0.003)\end{array}$ & $\begin{array}{l}\text { Age at onset } \\
\text { of retinopathy } \\
\text { (years) }\end{array}$ \\
\hline $0-4$ & 48 & 12.1 & 18.1 & 15.4 \\
$5-9$ & 83 & 8.9 & 12.7 & 16.9 \\
$\geqslant 10$ & 100 & 6.6 & 10.4 & 18.9 \\
\hline $\begin{array}{l}\text { Total } \\
\text { population }\end{array}$ & 231 & 9.1 & 14.1 & 17.5 \\
\hline
\end{tabular}

10 years, $92 \%$ after 15 years, and $100 \%$ after 20 years of diabetes respectively.

Their distribution over the different stages of retinopathy at the end of the study is demonstrated in Table 1 . While one-half of all positive findings were classified as minimal (stage 1 in 54 out of $109=50 \%$ ) and another substantial proportion, i.e. $26 \%(28 / 109)$ had background retinopathy (stages $3 \mathrm{a}$ and $3 \mathrm{~b}$ ), relatively few patients showed stage 2 changes $(17 / 109=16 \%)$. This evidence was interpreted to indicate that stage 2 may represent a transitional stage between incipient (only angiographically detectable microvascular retinal changes) and background retinopathy. In 10 patients ( 9 females, 1 male), i.e. in $9 \%$ of positive findings and $4 \%$ of the total sample, proliferative changes (stage 4) were found which necessitated photocoagulation after $12 \pm 3$ (range 8 to 18 ) years of diabetes duration.

From life-table analysis, the median latency period between the onset of diabetes and the development of angiographically positive early retinal changes was 9.1 years (8.7 years in males, 9.4 years in females, $p=\mathrm{NS}$ ). When only ophthalmoscopy was used, this period was found to be prolonged to 13.3 years (Fig. 3). Fluorescein angiography, therefore, detects retinopathy 4 years earlier than ophthalmoscopy. In some patients, even stage 3 angiographic changes, which may precede proliferative retinopathy, were interpreted at ophthalmoscopy as minimal changes only or were not detected at all.

The life-table analysis also permitted the calculation of the risk of developing retinopathy at any time after the onset of diabetes as long as the patient was still free from retinal lesions (Fig. 4). At the onset of diabetes, the median expectation of early retinopathy ( 9.1 years, see above) had an $80 \%$ probability range between 4.7 years $\left(10^{\text {th }}\right.$ percentile) and 15.1 years $\left(90^{\text {th }}\right.$ percentile). In other words, every patient in this sample had a $10 \%$ chance of developing early retinal changes within less than 5 years, and a $90 \%$ chance of reaching this point within 15 years. This wide time variation of more than 10 years, on the other hand, suggests that other factors apart from diabetes duration may greatly modify the risk of developing retinopathy.

After 5, 10 and 15 years of diabetes duration without retinopathy, the median risk of developing early structural changes was $9.8,13.5$ and 16.9 years, respectively, with a constantly narrowing $80 \%$ probability range (Fig.4). This indicates the increasing importance of diabetes duration as the major or, after 20 years, the only determinant of retinopathy.

The risk of developing early retinal changes was greatly influenced by the age at the onset of diabetes. Earlier onset of diabetes was associated with a significantly longer, later manifestation with a shorter period of freedom from retinal changes. In patients stratified according to their age of onset, below 4 years, between 5 and 9 years, and above 10 years of age, the median latency was $12.1,8.9$ and 6.6 years respectively $(p<$ 0.0001 ) (Fig. 5, Table 2).

The median risk age for the development of retinopathy was calculated as 17.5 years. Logically, the great variation of the latency period, which depended upon the age at onset of diabetes, will also be reflected in vari- 


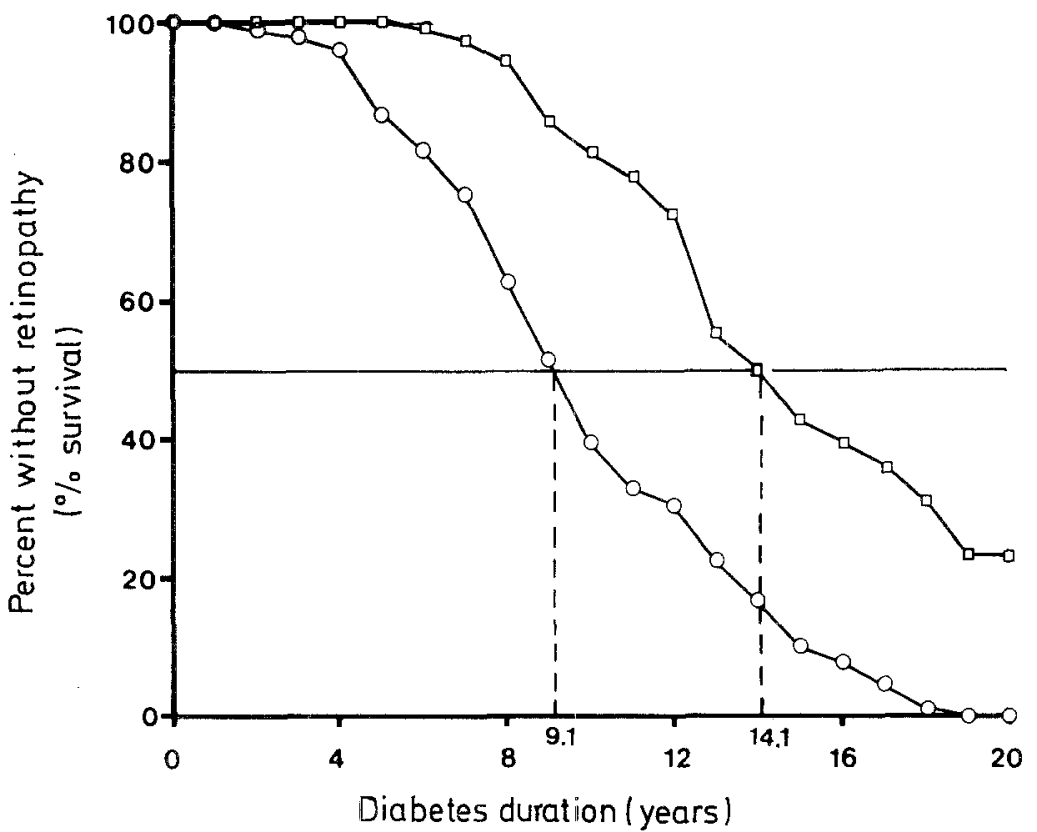

Fig. 6. Life-table analysis of stages 1 (minimal) and $3+$ (background + proliferative) retinal lesions in 231 patients. With respect to the more severe lesions, $20 \%$ of the subjects remained free from retinopathy after 20 years, while minimal lesions were documented in all. $\mathrm{O}=$ early stages, $\square=$ stages $3+$. The horizontal line indicates the median survival ations of the median chronological age at the 'onset' of retinopathy. In fact, in those sub-groups mentioned in the previous paragraph, the median age at the detection of early retinal changes was calculated to be $15.4,16.9$ and 18.9 years respectively ( $p<0.0001$, Table 2$)$, indicating that diabetic children do not tend to develop retinopathy before 15 years of age.

Since only background retinopathy (stage $3+$ ) may be considered as representing a 'point of no return' preceding proliferative lesions, the median risk of developing such lesions was also calculated. It was found to be 14.1 years, 5 years longer than the median latency period for the development of early changes (Fig.6). Even these preproliferative changes were dependent upon the age at onset of diabetes, and developed significantly later in patients with earlier diabetes manifestation $(p<$ 0.003 ) (Table 2). Late changes tended to occur more frequently in girls.

In some patients, angiographically detected microaneurysms regressed; this necessitated the reclassification of these patients into lower stages. This phenomenon, however, was limited to the early stages ( 1 and 2 ) of retinopathy, and remained temporary. It is doubtful, however, whether these changes represented true morphological regression or rather thrombotic closures of microaneurysms which may hamper their detection.

\section{Discussion}

Several authors $[4,5,7-9]$ have demonstrated previously that fluorescein angiography permits the detection of retinal changes in children and adolescents soon after the onset of diabetes. The present study tried to determine the prevalence of retinopathy in a large sample of young Type 1 diabetic subjects, and to define the influence of age and diabetes duration under generally constant conditions of treatment for many years. Some of the relationships suspected in the literature were confirmed in this study by statistical analyses.

By means of life-table analysis, the median risk of any subject (expressed in years from the onset of diabetes) of developing early retinal changes was found to be 9.1 years. Since, however, some patients had various degrees of retinopathy before the first angiographic documentation, this calculation is probably too long.

Compared with ophthalmoscopy as performed by an experienced ophthalmologist, fluorescein angiography allows the detection of retinal changes about 4 years earlier. This finding confirms the findings of Palmberg et al. [12]. In some patients, even more extensive changes, classified here as stage 3 , may be missed by ophthalmoscopy, although they are liable to rapidly progress to early proliferative retinopathy and thus require photocoagulation [13]. Considering the fact that the median latency period between fluorescein angiography stages 1 and 3 in this study was found to be 5 years and that fundoscopy detects retinal changes with a latency of 4 years compared with fluorescein angiography, some patients may require treatment shortly after their first detection of retinopathy by fundoscopy. A further disadvantage of ophthalmoscopy is that the majority of changes may be less pronounced and that leakage is more difficult to detect. If only one of the generally requested annual fundoscopies is missed, even proliferative changes may develop in a previously 'normal' fundus from one examination to another within only two years. These considerations and the fact that fluorescein angiography seems to be a practically innocuous procedure in children and adolescents $[4,5,14]$ seem to justify the routine application of fluorescein angiography in young patients over 15 years of age and diabetic for more than 5 years.

We have also confirmed earlier reports [10-12, 15-17] relating the age at onset of diabetes to the development of retinopathy. Children of preschool age at the 
onset of diabetes stay free from even minimal retinal complications longer than adolescents. This finding suggests that age exerts an independent influence on retinopathy development apart from that of diabetes duration. Furthermore, the 'onset' of retinopathy over 15 years of age in the great majority of subjects [10-12, $17,18]$ suggests some influence of sexual maturation during puberty. According to the results of this study, children under 15 years of age and diabetic for less than 5 years usually need not be bothered with angiography, as even minor changes are rarely observed in this age group.

Since retinal changes in this study were never found at onset, but only after several years of diabetes, the disease itself seems to induce the development of retinopathy [10-12]. It is likely that the finding of early structural changes shortly after the onset of diabetes $[5,7,8,19]$ is due to an over-interpretation of angiographic findings; in any case, they are not reproducible.

Our finding that all patients with long-term diabetes develop microvascular changes contradicts earlier reports [1-3,20-23] where up to $20 \%$ of the subjects were found to be free from vascular complications even after decades of diabetes. This discrepancy may be due to minimal changes being missed by ophthalmoscopy and being detected only by fluorescein angiography. Why some subjects develop mild changes only, in spite of a long duration of disease, remains unknown.

The present study indicates that retinopathy begins only a few years after the onset of Type 1 diabetes in young patients. Most of the lesions discovered in childhood and adolescence are minimal and may, for some years, be missed by fundoscopy. The median latency period between onset of diabetes and development of retinopathy appears to be about 9 years. Only 5 years later, retinal changes reach the proliferative state of no return. This study confirms the influence of both duration and age at onset of diabetes upon the development of retinopathy. A detailed analysis of further risk factors is presented in the accompanying paper.

Acknowledgements. This study was supported by the Volkswagen Foundation (Stiftung Volkswagenwerk).

\section{References}

1. Lestradet H, Papoz L, Hellouin de Menibus C, Levasseur F, Besse J, Billaud L, Batistelli F, Tric P, Lestradet F (1981) Long-term study of mortality and vascular complications in juvenile onset (Type I) diabetes. Diabetes 30: 175-179

2. Deckert T, Poulsen JE, Larsen M (1978) Prognosis of diabetics with diabetes onset before the age of thirty-one. I and II. Diabetologia 14: 363-370, 371-377

3. Pirart J (1977) Diabète et complications dégénératives. Présentation d'une étude prospective portant sur 4400 cas observés entre 1947 et 1973. Diabete Metab 3:97-107, 173-182, 245-256

4. Hövener G, Oberdisse U, Burger W, Weber B (1981) Development of retinopathy in diabetic children and adolescents related to long-term metabolic control. In: Weber B (ed) Diabetic angiography. Pediatric and adolescent endocrinology, vol 9. Karger, Basel, pp 226-231

5. Malone JI, van Cader TC, Edwards WC (1977) Diabetic vascular changes in children. Diabetes 26: 673-679

6. Nie NH, Hull CH, Jenkins JG, Steinbrenner K, Bent DH (1975) SPSS - Statistical package for the social sciences, 2nd edn. McGraw-Hill, New York

7. Barta L, Brooser G, Molnar M (1971) Diagnostic value of retinal fluorescence angiography in juvenile diabetes. Acta Pädiat Sci Hung 12: 243-248

8. Dorchy H, Toussaint D, Devroede M, Ernould C, Loeb H (1977) Diagnostic de la rétinopathie diabétique infantile par angiographie fluorescéinique. Description des lésions initiales. Nouv Presse Med 6: 345-347

9. Hoffmann K, Gilde K, Hürter P, Jost J (1980) Diabetische Retinopathie bei Kindern und Jugendlichen. Ihre Abhängigkeit von der Stoffwechseleinstellung. Klin Monatsbl Augenheilkd 117: 482-486

10. Frank RN, Hoffmann WH, Podgor MJ, Joondeph HC, Lewis RA, Margherio RR, Nachazeh DP jr, Weiss H, Christopherson KW, Cronin MA (1982) Retinopathy in juvenile-onset type I diabetes of short duration. Diabetes 31: 874-882

11. Jackson RL, Ide CH, Guthrie RA, James RD (1982) Retinopathy in adolescents and young adults with onset of insulin-dependent diabetes in childhood. Ophthalmology 89:7-13

12. Palmberg $P$, Smith $M$, Waltmann $S$, Krupin T, Singer $P$, Burgess $P$, Wendtlant T, Achtenberg OJ, Cryer P, Santiago J, White N, Kilo C, Daughaday W (1981) The natural history of retinopathy in insulin-dependent juvenile-onset diabetes. Ophthalmology 88: 613-618

13. Hövener G (1984) Fluoreszenzangiographische Untersuchungen bei insulinabhängigen juvenilen Diabetikern. Frühe Diagnose, Häufigkeit und Entwicklung der Retinopathie. Art und Zeitpunkt der Therapie (Photokoagulation). Habilitationsschrift, Freie Universität Berlin

14. Frost-Larsen $\mathrm{K}$, Starup $\mathrm{K}$ (1980) Fluorescein angiography in diabetic children. A follow-up. Acta Ophthalmol 58:355-360

15. L'Esperance FA jr, James WA (1981) Diabetic retinopathy. Epidemiology. In: Diabetic retinopathy. CV Mosby, St Louis Toronto London, pp 20-37

16. Marquardt C, Gliem H (1978) Probleme der Retinopathie bei Diabetesmanifestation im Kindesalter. Pädiatr Grenzgeb 17: 203-212

17. Fischer F (1976) Diabetes mellitus: Pubertät und Angiopathie. Wien Klin Wochenschr 88: 51-53

18. Imerslund $O(1959)$ The prognosis in diabetes with onset before age two. Acta Paediatr 49: 243-248

19. Brooser G, Barta L, Anda L, Molnar M (1975) Frühdiagnose der Mikroangiopathie bei kindlichem Diabetes. Klin Monatsbl Augenheilkd 166: 233-236

20. Lukens FDW, Franklin SN (1966) Long-term diabetes without vascular disease. Med Clin N Am 1385-1391

21. Rosenbloom AL (1977) Nature and nurture in the expression of diabetes mellitus and its vascular manifestations. Am J Dis Child 131: 1154-1159

22. Larsson Y, Sterky G (1962) Long-term prognosis in juvenile diabetes mellitus. Acta Paediatr 51 (Suppl): 130

23. Knowles HC jr (1971) Long-term juvenile diabetes treated with unmeasured diet. Trans Ass Am Phys 85: 95-101

Received: 28 December 1984

and in revised form: 21 October 1985

Dr. Bruno Weber

Universitäts-Kinderklinik

Heubnerweg 6

D-1000 Berlin 19 